\title{
CORRECTIONS
}

\section{GMC impartiality double standards}

During the editing process we misinterpreted the last line of Peter Wilmshurst's Letter (BMJ 2013;346:f27, doi:10.1136/bmj. f27) so that it was edited to read: "Mullen and the GMC are right to expect impartiality in those analysing evidence when the livelihood of a doctor is at stake, but not when the lives of patients are at risk." Peter Wilmshurst wanted to correct his meaning here, which would have been more accurately expressed by the sentence: "Mullen and the GMC are right to expect impartiality in those analysing evidence when the livelihood of a doctor is at stake, but wrong not to expect it when the lives of patients are at risk."

Cite this as: BMJ 2013;346:f193

๑ BMJ Publishing Group Ltd 2013 